\title{
POPULATION TRENDS AND CONTROLS IN UNDERDEVELOPED COUNTRIES*
}

\author{
A. J. JAFFe† \\ INTRODUCTION
}

\section{A. What Are Underdeveloped Areas?}

The term "underdeveloped" areas encompasses a great variety of socioeconomicdemographic situations. The countries of Africa, Asia, and Latin America, which are often referred to in the literature as the underdeveloped parts of the world, are all very different from each other in many respects, both economic and noneconomic. The noneconomic differences, comprising as they do language and observable social customs, are immediately recognizable to even the most casual of observers.

The economic differences may be less noticeable, however, especially to the tourist who sees but the capital cities. Nevertheless, some idea of the great variation that exists can be obtained by noting that annual per capita national income in Puerto Rico is over $\$ 400$. This is about double that of Mexico; which, in turn, may be about double that of Guatemala or Honduras; which, in turn, may be about double that of Bolivia. Thus, within Latin America-an underdeveloped area-the most prosperous (or least underdeveloped) country may be perhaps ten times as well off as the poorest. When compared with the United States, which has an annual per capita national income of over $\$ 2,000$, however, even the most prosperous of the Latin American countries appears underdeveloped.

Still, these countries of Africa, Asia, and Latin America all have in common the fact that their economic development-as measured in either annual per capita national income or annual per capita use of inanimate energy-is very much below that of North America and northwestern Europe. Hence, we are justified in examining them as a group of countries that are economically quite different from ourselves. We ask the reader, however, to keep in mind the fact that large differences among countries do exist and that any generalizations that we shall make do not necessarily apply uniformly to all underdeveloped countries.

* The writer wishes to thank Mr. William Abraham and Mr. A. Aidenoff for their advice on economic aspects, but he alone assumes full responsibility for the findings presented in this article. Unless ascribed to other sources, the data upon which this article is based have been drawn from various U.N. publications and reports.

Columbia University Bureau of Applied Social Research Pub. No. A-317.

† A.B. 1935, A.M. 1938, Ph.D. I94I, University of Chicago. Director, Manpower and Population Program, Bureau of Applied Social Research, Columbia University. Author, People, Jons and Economic Development (x959); [with C. D. Stewart] Manpower Resources and Utilization (1951); [with R. O. Carleton] Occupational Mobility in THE UNired States, I930-rg60 (1954). Contributor to demographic periodicals. 
Similar observations can also be made about the variation within the countries of North America, Europe, Oceania, and the Soviet Union, which we group together as the "developed" areas. Indeed, some students have included southern and eastern Europe with the underdeveloped areas. For the sake of simplicity and on the grounds that substantially the same results will emerge, however, we prefer to allocate entire continents to one or the other group of countries.

But with respect to demographic characteristics, we do wish to emphasize here, in anticipation of our subsequent discussion, that very many of these underdeveloped countries do seem to be rather similar. Certainly, there is less variation with respect to rates of population growth and population characteristics than there is with respect to income or energy consumed. Hence, despite the fact these countries may differ considerably in economic position, enough of them are sufficiently similar demographically to warrant our discussing population trends in underdeveloped countries.

Before proceeding to our analysis, we must bring to the reader's attention the fact of the paucity of reliable data covering all of the underdeveloped countries. We have pieces of information about many countries, but complete information about none. Hence, we are often forced to speak in broad and general terms in order to spread a limited amount of factual information over a large number of countries.

\section{B. The Interrelated Matrix of Factors ${ }^{1}$}

Population changes are but one element in an interrelated matrix of events. Demographic trends, like economic development, are an integral part of an entire process of socioeconomic-demographic changes. If one factor changes, others must also. These changes do not necessarily occur simultaneously; furthermore, we do not know enough to be able to predict the exact relationship between any two variables, so that we cannot always estimate the amount or nature of change that will be produced in variable $b$ if we know that variable $a$ changes in a certain manner.

Why should we be concerned with knowing the precise relationships among. the variables? The answer is simply this: if we really understood them, then we could predict future demographic trends in the underdeveloped countries on the basis of current socioeconomic information. Although our knowledge is limited, we do have considerable factual information about such elements as current rate of economic growth, rate of capital formation, extent of literacy and school attendance, degree of urbanization, etc. We even have some information regarding the political and social aims and aspirations of peoples, their attitudes toward work versus leisure, their religious attitudes, etc. If we were now able to wrap all of these into a neat: prediction equation-one that would take into consideration both the manner in which these factors will influence future demographic changes and the manner in which such demographic changes will influence these other variables-then we

\footnotetext{
${ }^{1}$ For further discussion of this point, see, e.g., A. J. Jaffe \& C. D. Stewhrt, Manpower Resources. AND Utilization ch. 2 I (I95I).
} 
could predict exactly what population changes will occur in the various underdeveloped parts of the world.

Clearly, we cannot present the reader with a complete matrix of factors. All we can do is state emphatically that changes in demographic characteristics-particularly a lowering of fertility and rates of population growth-will not occur in the absence of other fundamental changes in the social and economic structures. Hence, in the following pages, we shall examine a few factors that we believe influence birth rates and population growth and then describe how population growth, in turn, influences economic progress-the rise from underdeveloped, to semideveloped, to fully-developed economies. This latter does not imply that all parts of the world will necessarily become fully-developed economies. Maybe some day all parts of the world will be on about the same economic level; on the other hand, it is possible that economic growth will continue throughout the world so as to maintain a large advantage for the presently developed countries. To the extent, then, that "underdeveloped" is a relative concept, many parts of the world will continue to be underdeveloped for the next few generations or longer, no matter how much growth they may achieve, simply because the United States, Canada, Europe, Oceania, and the Soviet Union will continue to grow also.

\section{The Time Factor}

When discussing population trends, obviously we are utilizing time as one of the dimensions under consideration. Furthermore, we are concerned largely with studying the past and present in order to estimate the future. Now, our concern is with the short-run future, rather than the long-run. We emphasize this distinction since so much of the present-day discussion is made fruitless by the adversaries talking about different "futures"-as, for example, the futile discussion in which Paul Hoffman talked of the problems he faced during the rg6o's and Colin Clark talked aimlessly about some indefinite period two or more centuries into the future. ${ }^{2}$ On the grounds that we can discuss most intelligently only the next two or three decades, we are limiting our analysis to such a short-run period. To discuss a longer period, one must be either a Nostradamus or an ancient Biblical prophet, or one must talk from faith rather than facts. We are neither of the former, and are trying to limit ourselves to facts.

\section{I}

\section{ThE BACKground}

\section{A. Population Growth}

During the first two decades of the twentieth century, the population of developed countries-i.e., North America, Europe including the Soviet Union, and Oceaniagrew at an annual rate of one per cent or slightly less; that of the remaining

a CBS Reports, The Population Explosion (as broadcast over the CBS Television Network, Jan. 14, I960). 
countries, the underdeveloped parts of the world, grew at half this rate, or slightly less-as is shown in table one. The great variation among countries during this period can be seen from the fact that the population of Japan grew at a rate of about I.3 per cent annually, whereas that of the rest of Asia grew at a rate of about 0.2 per cent. The population of Latin America, on the other hand, grew at a rate of some 2.I per cent annually during the period Ig00 to I920; and that of North America, part of the economically developed world, grew at exactly the same rate. Clearly, there was very wide variation among the several parts of the world. We can only say that on the whole, population growth in the developed parts of the world was much more rapid than in the underdeveloped parts.

\section{TABLE I}

Average Annual Rates of Population Growth by Continents and Regions: rgo0-57 (PERCENTAGE)

\begin{tabular}{|c|c|c|c|c|}
\hline Regions & $1900-20$ & $1920-40$ & $1940-50$ & 1950.57 \\
\hline 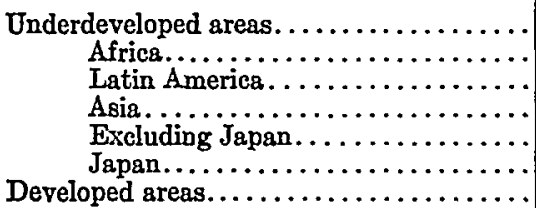 & $\begin{array}{l}0.4 \\
0.7 \\
2.1 \\
0.2 \\
0.2 \\
1.3 \\
0.9\end{array}$ & $\begin{array}{l}1.3 \\
1.0 \\
2.1 \\
1.1 \\
1.1 \\
1.3 \\
0.9\end{array}$ & $\begin{array}{l}1.5 \\
1.5 \\
2.3 \\
1.2 \\
1.2 \\
1.6 \\
0.3\end{array}$ & $\begin{array}{l}1.9 \\
1.8 \\
2.6 \\
1.8 \\
1.8 \\
1.3 \\
1.2\end{array}$ \\
\hline
\end{tabular}

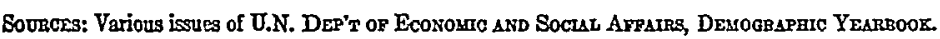

World War I seems to have marked a turning point. Between I920 and $x 940$, the rate of population growth in the underdeveloped parts of the world increased to about I.3 per cent annually, while that in the developed parts of the world remained at about one per cent or slightly under. Since I920, the underdeveloped parts of the world have continued to forge ahead, and during the period $195^{\circ}$ to $\mathrm{r} 957$, their population grew about half again as rapidly as did those of the developed countries.

It may be of interest to note that war, as a Malthusian device for slowing population growth, seems to be operative on the developed parts of the world rather than the underdeveloped. During the decade 1940 to x950, encompassing World War II, the developed countries grew at a rate of about 0.3 per cent annually, as contrasted with a 1.5 per cent rate of growth in the underdeveloped areas.

\section{B. Present Distribution of Population}

Examination of the distribution of the world's population by continents and subcontinents-as is shown in table two-reveals the approximate distribution of the underdeveloped areas. Asia contains over one-half of the world's population. Mainland China alone may contain about one-quarter of all the human race. Latin America and Africa each contains a little under one-tenth of the total. 
TABLE II

Population of the World by Continents and Regions: 1920-57 (Millions) ${ }^{\mathfrak{a}}$

\begin{tabular}{|c|c|c|c|c|}
\hline Regions & 1920 & 1940 & 1950 & 1057 \\
\hline 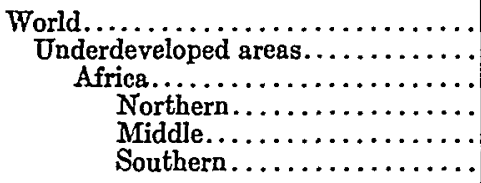 & $\begin{array}{r}1,810 \\
1,198 \\
140 \\
- \\
-\end{array}$ & $\begin{array}{r}2,246 \\
1,516 \\
172 \\
37 \\
123 \\
12\end{array}$ & $\begin{array}{r}2,492 \\
1,738 \\
199 \\
43 \\
142 \\
14\end{array}$ & $\begin{array}{r}2,795 \\
1,973 \\
225 \\
50 \\
158 \\
17\end{array}$ \\
\hline $\begin{array}{r}\text { Latin America } \ldots \ldots \ldots \ldots \ldots \ldots \ldots \ldots \ldots \ldots \ldots \\
\quad \text { Middle } \ldots \ldots \ldots \ldots \ldots \ldots \ldots \ldots \\
\text { Southern } \ldots \ldots \ldots \ldots \ldots \ldots\end{array}$ & $\begin{array}{l}91 \\
30 \\
61\end{array}$ & $\begin{array}{r}131 \\
41 \\
90\end{array}$ & $\begin{array}{r}163 \\
51 \\
112\end{array}$ & $\begin{array}{r}192 \\
61 \\
131\end{array}$ \\
\hline 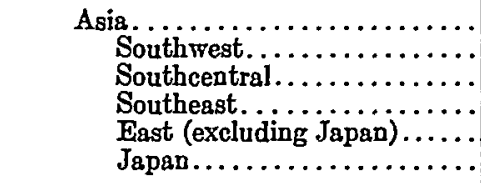 & $\begin{array}{r}967 \\
44 \\
326 \\
110 \\
431 \\
56\end{array}$ & $\begin{array}{r}1,213 \\
54 \\
410 \\
155 \\
523 \\
71\end{array}$ & $\begin{array}{r}1,376 \\
61 \\
466 \\
171 \\
595 \\
83\end{array}$ & $\begin{array}{r}1,556 \\
72 \\
513 \\
193 \\
687 \\
91\end{array}$ \\
\hline 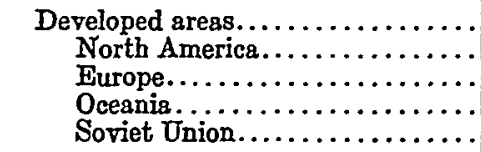 & $\begin{array}{r}612 \\
117 \\
328 \\
9 \\
158\end{array}$ & $\begin{array}{r}730 \\
146 \\
380 \\
11 \\
192\end{array}$ & $\begin{array}{r}754 \\
168 \\
393 \\
13 \\
181\end{array}$ & $\begin{array}{r}822 \\
180 \\
414 \\
15 \\
203\end{array}$ \\
\hline
\end{tabular}

Norz: 2 Due to rounding, the sums may not necessarily equl the totals shown.

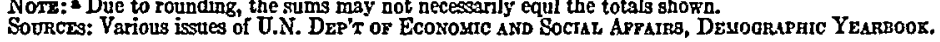

The rest of the world, euphemistically referred to as the "developed" areas, consists of North America and the Soviet Union, each containing about seven per cent; Europe, containing about fifteen per cent; and Oceania, containing about one-half of one per cent of the total world population. If we define the most developed parts of the world as consisting of North America, northern and western Europe, and Oceania, we find that these areas contain just one-eighth of the human race.

From the viewpoint of its relevancy for the future economic growth of the underdeveloped areas, therefore, we can say that less than one-quarter of the world's population is being called upon to supply much-if not most-of the capital investment needed by some three-quarters of the world's people.

\section{Births, Deaths, and Natural Increase}

Population growth for any given country results from an excess of births over deaths and an excess of immigrants over emigrants. Historically, migration has been of very great importance in certain parts of the world and at certain times. Thus, for example, the nineteenth century witnessed the great exodus from Europe to the Western Hemisphere, resulting in a decreased rate of population growth in Europe and an accelerated rate of population growth in the New World. During the twentieth century, however, intercontinental migration has played but a minor 
TABLE III

Estimated Vital Rates by Continents and Regions: Middde i930's and Mrddle x950's

(PER IOOO POPULATION)

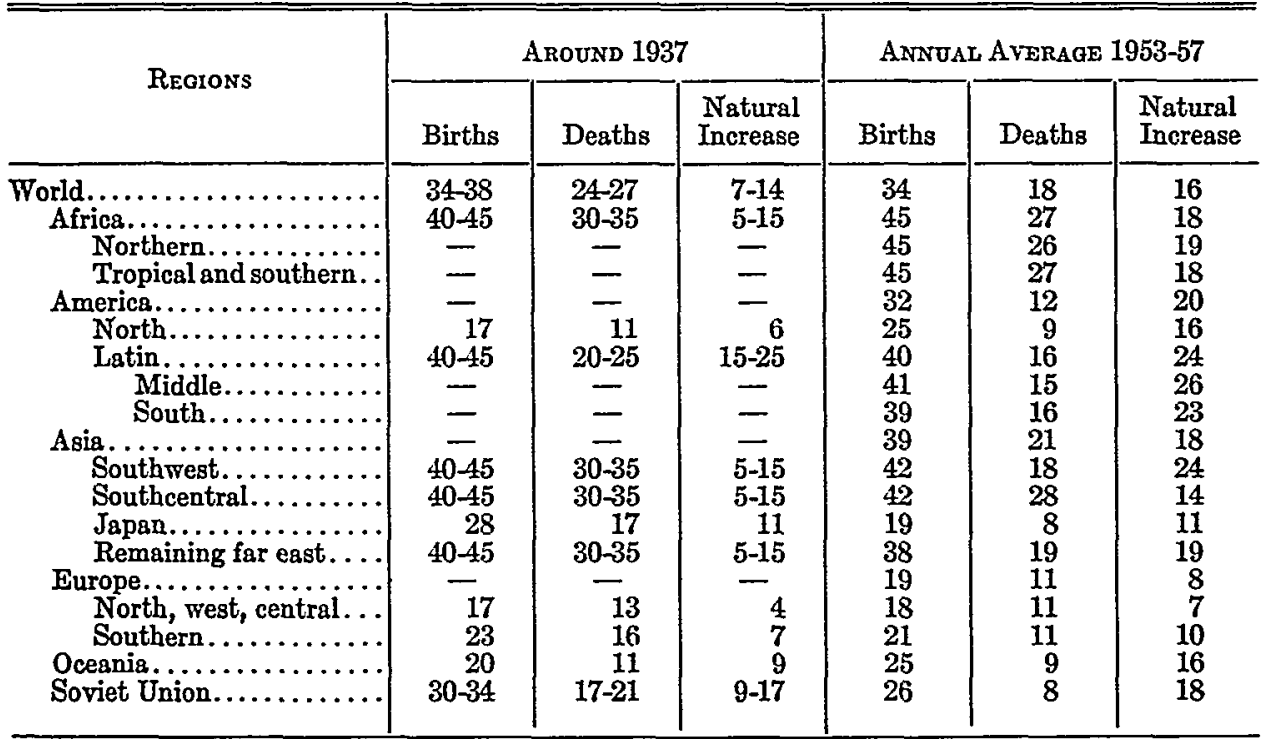

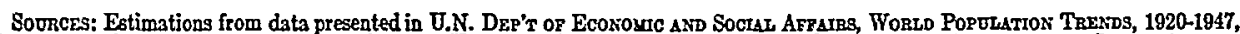

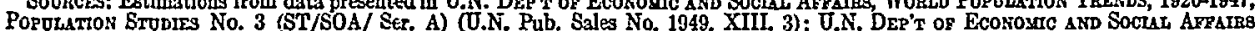
Dexographic Yearboor table 2 (U.N. Pub. Sales No. 1958, XIII, 1),

role in affecting the rate of population growth. ${ }^{3}$ Accordingly, let us turn to a closer examination of birth and death rates.

In the underdeveloped parts of the world-as is shown in table three-the birth rate, expressed as annual births per I,000 population, is about forty or more. Africa may have a birth rate of about forty-five, and Latin America and Asia of perhaps forty. In numbers of births, these rates mean that during the $1950^{\circ}$ 's, there were about ro,000,000 births in Africa annually, about 8,000,000 in Latin America, and over 60,000,000 in Asia-for a grand total of some 80,000,000 births annually.

In the developed parts of the world, the birth rate is about half as high. In Europe, it was about nineteen during the $1950^{\circ}$ 's, and in North America, Oceania, and the Soviet Union, about twenty-five. Altogether, there were about $18,000,000$ births annually.

Death rates, like birth rates, are very high in the underdeveloped parts of the world. In Africa, expressed as annual deaths per 1,000 population, it is estimated to be about twenty-seven, in Asia, perhaps twenty-one, and in Latin America, about sixteen. Thus, in the underdeveloped areas of the world, there are over 40,000,000 deaths annually. The excess of births over deaths, hence, amounts to a little less than $40,000,000$ annually. The population in the totality of the underdeveloped areas of the world, therefore, grows at a rate of about two per cent annually.

${ }^{3}$ For further discussion of migration, see, e.g., Eugene Kulischer, Migration, I5 Excrc. Brir. 462 (1956 ed.) 
In the developed parts of the world, the death rate is about ten; and there are an estimated 8,000,000 deaths annually. The average annual excess of births over deaths, hence, amounts to about $\mathrm{r} 0,000,000$. This implies a rate of population growth of a little over one per cent annually.

In summary then, during the 1950 's, the rate of population growth was much higher in the underdeveloped areas of the world than in the developed, largely because of the much higher birth rate. That the rate of population growth is not higher than that observed-almost two per cent annually in the underdeveloped areas-is ascribable entirely to the fact that death rates are still high, and about double those in the developed parts of the world.

Death rates, however, have been declining throughout the world-as is also shown in table three-particularly in the decade and a half following World War II. All of the underdeveloped areas have not experienced the same decreases; indeed, some probably have as high a rate of mortality in 1960 as a generation earlier. What is most important is the fact that in those countries in which there was a sharp drop in the death rate, there was virtually no drop in the high birth rate. As a result, the rate of population growth has increased significantly and promises to increase even more as further efforts are made to reduce the death rates.

Ceylon is often cited as an example of how rapidly mortality levels can be reduced and the immediate effects of such reductions upon population growth. In 1945, Ceylon had a birth rate of about thirty-seven and a death rate of about twenty-two, leaving a rate of natural increase of fifteen. Various public health measures introduced in the late 1940's brought the death rate down, and in 1957, a rate of ten was reported. The birth rate, however, continued unchanged, and a rate of thirty-seven was reported in I957 also. The rate of population growth thus increased from fifteen to twenty-seven.

In the economically-more-developed countries also, there were decreases in mortality rates during recent years, accompanied in some cases by increases in fertility rates. Both birth and death rates in these countries are sufficiently low, however, so that the rate of population increase remains considerably below that of the underdeveloped countries. Furthermore, death rates in the developed countries cannot drop very much more, so that there is little likelihood of increased rates of population growth in the future.

\section{II}

\section{Socionconomic Factors Related to Population Growth}

As we mentioned earlier, birth and death rates are parts of an interrelated matrix of social and economic factors; changes in any one part of this matrix ultimately result in changes in all other parts. These changes are not necessarily instantaneous; perhaps several decades may elapse between the time one element changes and other elements follow suit. Furthermore, our knowledge is too limited to specify 
the exact natures of these interrelationships. Accordingly, in the following pages, we shall examine some of the factors that are associated with birth and death rates and note how these factors may be changing. On the basis of such historical observations, we can make some efforts at estimating possible future developments and their possible repercussions on the vital rates and the rate of population growth.

\section{A. Inanimate Energy Consumed}

Perhaps the best single index of technical and economic development is afforded by the amount of inanimate energy-i.e., energy derived from coal, oil, water power, and other nonhuman or animal sources-consumed per person-as is shown in table four. A modern economy is based on the use of such energy; the economically underdeveloped areas characteristically use human and animal power. The range in the use of inanimate energy is very great and is in the order of yooo to one. The United States consumed over 7,000 kilograms of energy per capita in 1958 , whereas some countries, as Afghanistan, for example, consumed under ten.

TABLE IV

Estimated Consumption of Inanimate Energy by Continents and Regrons: x929-58

\begin{tabular}{|c|c|c|c|c|c|c|c|}
\hline \multirow{2}{*}{ ReGion } & \multicolumn{3}{|c|}{$\begin{array}{c}\text { Total METRIC ToNs } \\
\text { (millions) }\end{array}$} & \multicolumn{2}{|c|}{$\begin{array}{c}\text { Kilograms Per } \\
\text { Capita }\end{array}$} & \multicolumn{2}{|c|}{$\begin{array}{c}\text { Percentage } \\
\text { Crange 1950-58 }\end{array}$} \\
\hline & 1929 & 1950 & 1958 & 1950 & 1958 & Total & $\underset{\text { Per }}{\text { Capita }}$ \\
\hline 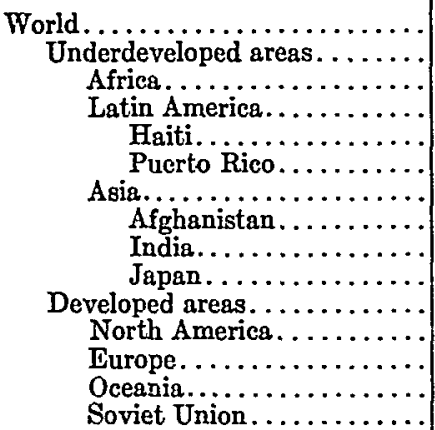 & $\begin{array}{r}1799 \\
155 \\
17 \\
27 \\
.015 \\
3 \\
111 \\
a \\
25 \\
47 \\
1644 \\
858 \\
697 \\
15 \\
73\end{array}$ & $\begin{array}{r}2677 \\
278 \\
40 \\
66 \\
.059 \\
1.100 \\
172 \\
.057 \\
36 \\
64 \\
2399 \\
1230 \\
781 \\
32 \\
356\end{array}$ & $\begin{array}{r}3699 \\
600 \\
63 \\
122 \\
.100 \\
3.100 \\
415 \\
.110 \\
55 \\
80 \\
3099 \\
1421 \\
1035 \\
43 \\
600\end{array}$ & $\begin{array}{r}1070 \\
160 \\
200 \\
410 \\
20 \\
480 \\
140 \\
3 \\
100 \\
780 \\
3180 \\
7420 \\
1990 \\
2500 \\
1780\end{array}$ & $\begin{array}{r}1300 \\
300 \\
271 \\
620 \\
30 \\
1360 \\
264 \\
8 \\
137 \\
870 \\
3700 \\
7420 \\
2470 \\
2880 \\
2900\end{array}$ & $\begin{array}{r}38 \\
116 \\
59 \\
86 \\
70 \\
180 \\
140 \\
90 \\
150 \\
25 \\
29 \\
16 \\
33 \\
35 \\
68\end{array}$ & $\begin{array}{r}20 \\
88 \\
36 \\
50 \\
50 \\
180 \\
90 \\
170 \\
37 \\
12 \\
12 \\
0 \\
24 \\
15 \\
63\end{array}$ \\
\hline
\end{tabular}

Norz: : Not available.

SoUrces: U.N. Statistical Papers, World Eivergr Sopplms in Selected Yeabs, 1929-1950 (ST/STAT/Ser. J/1) (U.N. Pub. Salea No.1952. XVIL. 3); World ENERGY Supplies 1050-1953 (ST/STAT/Ser.J/3) (U. N. Pub. Sales No. 59. XVII. 7 ) (1960).

Since some of this energy is used for heating it might be thought that countries in warm climates would, of necessity, consume less energy. Even within the tropics, however, we find very great variations. Thus, Puerto Rico annually consumed over r,300 kilograms per capita, whereas Haiti, hardly roo miles away, consumed only about thirty. On the basis of all other information available, we know that Puerto Rico is a much more developed area than is Haiti. In Asia and Africa, annual per capita consumption of energy amounted to between 260 and 270 kilograms; in Latin 
America, it was a little over 600. For all the underdeveloped areas combined, annual consumption was estimated to be about 300 kilograms of energy per capita.

Within the developed parts of the world, there was also considerable variation in energy consumption. Thus, the North American population annually consumed over 7,000 kilograms of energy per capita, whereas in Europe, Oceania, and the Soviet Union, between 2,500 and 3,000 were consumed. For the developed area as a whole, annual consumption averaged about 3,700 kilograms of energy per capita, or twelve times as much as in the underdeveloped areas.

That technological and economic development has been proceeding over the last generation in the continents that we have included under the term "underdeyeloped" areas is clearly evident. In 1929, these underdeveloped areas had used about 155,000,000 metric tons of energy; two decades later, in 1950 , they used about three-quarters again as much. Because of population growth, annual per capita consumption of energy did not quite increase this much; nevertheless, it increased from r20 to 160 kilograms. Between 1950 and 1958 , however, there was a vast increase in the use of inanimate energy in the underdeveloped areas; annual per capita consumption almost doubled in eight years to reach a high of 300 kilograms. In light of available information on power-plant construction during the late 1950's and contemplated construction during the Ig60's, we have every reason to believe that the use of inanimate energy will continue to increase rapidly within the foreseeable future.

In the developed parts of the world, there was also a significant increase in the use of inanimate energy, but at a much slower rate of growth. Between 1929 and I958, annual consumption rose from about 3,200 kilograms per capita to 3,700. Nevertheless, despite the fact that energy use increased much more rapidly during the I950's in the underdeveloped parts of the world, the discrepancy between the developed and underdeveloped parts is still very great.

In anticipation of the following remarks on trends in income, we should note here that increases in power production may well precede the rise in income levels. Considerable investment is required in order to build new power plants, and a number of years may elapse before these investments begin to pay off in observable terms of increased national income. Hence, large increases in power production during the I950's may portend larger increases in income during the 1960 's than occurred during the I950's. The growth of power may also reflect the growth of the infrastructure-the roads and transportation, irrigation, power development, communication facilities, and other prerequisites without which modern economic growth would not occur.

\section{B. Income}

In most parts of Africa and Asia in the latter part of the r950's, annual per capita national income appears to have been under roo United States dollars. Latin American countries may have been slightly more prosperous; in the large majority, annual per 
capita national income seems to have been between roo and 299 United States dollars. By contrast, of the remaining parts of the world that we are defining as developed, in half of the countries, annual per capita national income was over 600 United States dollars. Within each of the two parts-the underdeveloped and the developedthere was tremendous variation. Thus, the most prosperous country in each group had an annual per capita national income on the order of ten times as great as that of the least prosperous.

Reliable information on the rates of economic change is available for only some of the countries and only for the first half of the $195^{\circ}$ 's-as is shown in table five. In Japan, the rate of growth-i.e., real product at constant prices-averaged 7.5 per cent annually. In Bolivia, on the other hand, it seems to have averaged about one-half of one per cent annually. In general, the few countries for which information is available experienced rates of growth of between two and seven per cent annually. These are all countries in which annual per capita product is estimated to be under 600 United States dollars. For much of Latin America, Asia, and most of Africa, no information is available, and we cannot even hazard a guess as to the possible rate of economic growth.

In the most-economically-developed countries, the rates of growth seem to have been about as high as those in the underdeveloped countries. Canada, France, Switzerland, and the United States grew at rates of over four per cent annually, and Sweden and the United Kingdom between three and four per cent. These are all countries in which the annual per capita product is estimated to be over goo United States dollars.

In terms of personal well-being, the important factor is the rate of growth per capita-i.e., after taking into account population growth. When this is done, it becomes clear that in many countries, much of the aggregate economic growth achieved was simply consumed by a larger population. Thus, for example, Costa Rica experienced the very rapid rate of economic growth of seven per cent annually; but population increased at a rate of about four per cent annually, cutting down the rate of growth of per capita real product to about three per cent annually. The Japanese economy also grew very rapidly and averaged about 7.5 per cent annually; the Japanese population, however, grew at a rate of only about 1.4 per cent annually, so that per capita real product increased some six per cent annually, or double that of Costa Rica.

We noted that the economies of many of the underdeveloped areas grew quite rapidly; we also saw that these countries are the ones with the higher birth rates. What is most significant to note is that even relatively rapid rates of economic growth do not automatically bring down fertility levels, at least within the space of one decade. For example, the Venezuelan economy grew at an estimated rate of over seven per cent annually; the birth rate in the latter part of the I940's was estimated to be about forty-one, and in the latter part of the I950's, about forty-six. The popu- 
TABLE $\mathrm{V}$

Estimated Average Annual Rates of Economic Growth for

Selected Countries: 1950-55

(REAL PRODUCT AT CONSTANT PRICES)

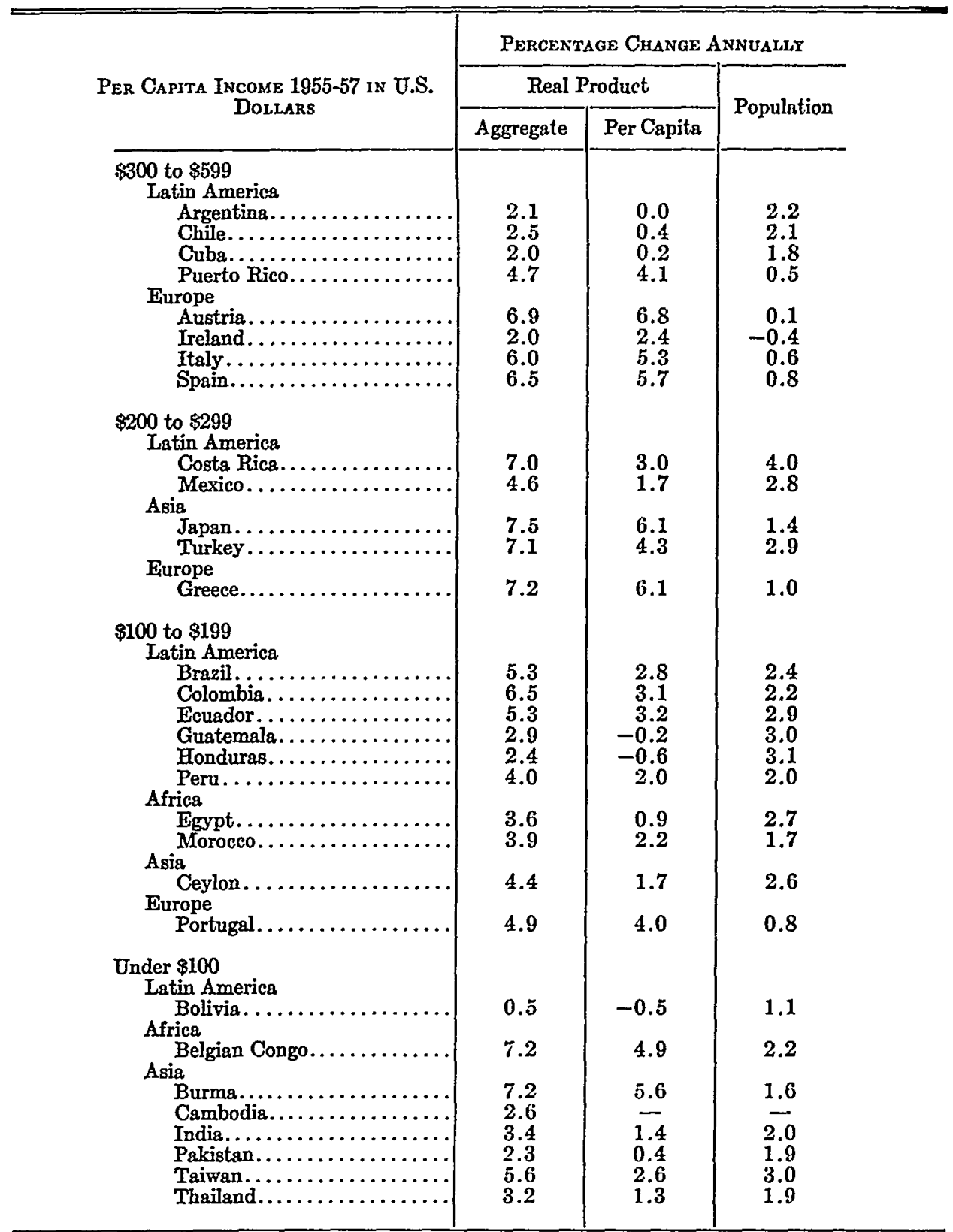

Sodrces: Statistical Office of the United Nations; various documents jncluding U.N. Yearboor of Natronal Accoonta STattorics (ST/STAT/Ser. H)for various years. 
lation of this country rose from $3,700,000$ in 1940 to $6,100,000$ in 1957 , or about sixty-five per cent. Again, in Costa Rica, with an economic growth rate of about seven per cent annually, the birth rate fell from perhaps forty-four to forty during the decade. The population increased from some 600,000 in 1940 to $1,000,000$ in I957, or about sixty-six per cent. In Taiwan, too, with an economic growth rate of five per cent, the birth rate remained virtually unchanged over the decade, about forty-four. The economy in Mexico grew almost as rapidly as in Taiwan. The birth rate, which was about forty-four throughout the $1940^{\circ}$ 's, may have risen to about fortyseven by the latter part of the r950's. The Mexican population grew from 19,700,000 in $I 940$ to $3 I, 400,000$ in $I 957$, or about sixty per cent.

In countries in which the economies grew at more modest rates, the economic changes had even less effect upon fertility and population growth. As we shall see subsequently, economic growth, together with other socioeconomic changes, ultimately will affect the level of the birth rate. But before the birth rates will decrease significantly, the size of the population may double, or more.

\section{Food Supply ${ }^{4}$}

Just as people in the underdeveloped parts of the world are poorer and use less inanimate energy, so they also eat less. The average number of calories consumed daily per capita during the I950's seems to have been under 2,600 in the large majority of the underdeveloped countries. Indeed, in some countries, such as India and the Philippines, for example, consumption may have been under 2,000 calories. In very few of the developed countries, on the other hand, has consumption been this low; in most of these countries, daily per capita food consumption appears to have been between 2,800 and 3,400 calories. The amount of food consumed varies greatly from one country to another, both within the developed and underdeveloped parts of the world. Furthermore, within each country, there must be very great variation among the different economic groups.

The Food and Agriculture Organization summarized the relationship between per capita national income (in United States dollars) and per capita quantity of food available for consumption (in terms of calories) $:^{5}$

... the general indications are ... that total food supplies for consumption rise rather sharply with income at the lowest income level, and then at a fairly constant rate until the highest income level, when the curve tends to flatten out.

In terms of the estimated requirements, the per capita number of calories of food available for consumption in the grossly underdeveloped countries is inadequate, according to the FAO analysis. In countries having an annual per capita national income of under 200 United States dollars, the supply seems to be less than the biological

\footnotetext{
'For a discussion of the role of land tenure, see, e.g., Clarence Senior, Land Reform and DeMOCRACX (1958).

${ }^{\circ}$ U.N. Food and Agriculture Organization, The State of Food and Agriculture 88 (x957).
} 
requirements. In countries above this national income level, the supply of calories seems to be greater than requirements.

In addition, the quality of the food eaten by the populace of the underdeveloped countries appears to be inferior to that eaten in the developed areas. Cereals and starchy foods constitute a much larger proportion of the diet in the poorer countries than in the economically-more-developed ones. Indeed, the average person in the United States probably consumes as food daily fewer calories from cereals and starchy foods than does the average Latin American. On the other.hand, per capita consumption of animal protein increases very sharply with increases in per capita income.

\section{The FAO report concluded: ${ }^{\circ}$}

... the common pattern of diet in most countries is a basis of cereals and starchy foods, supplemented to the extent that the consumer can afford by more expensive and attractive foods, including the so-called protective foods. When incomes first begin to rise above the subsistence level, the more expensive foods are largely additional to the basic diet. At higher income levels the consumption of the staple foods begins to decline and to be replaced by a larger intake of protective and other [more] expensive foods, which ultimately may make up the larger part of the diet. . . . This fact re-emphasizes the essential connection between economic development and nutritional improvement. Until productivity is raised and the general run of people in a country earn higher incomes, any substantial improvement in nutrition is unlikely....

Now, how does the long-run increase in population compare with possible trends in the volume of agricultural production? Available data for a number of countries -as is shown in table six-permit us to compare population and agricultural production changes from the mid-r930's to the mid-r950's. In some of the underdeveloped countries, as Thailand and Mexico, for example, the increases in agricultural production far outstripped population growth; in a number of other countries, population increase was greater than that of agricultural production (e.g., Egypt, Burma, Taiwan); and in a small number of countries, the two factors grew at about the same rate (e.g., Japan, Ceylon). On the other hand, in almost all of the countries of the developed areas-i.e., North America, Europe, and Oceania-the increase in agricultural production was considerably greater than the increase in population.

In summary, it would appear that for the world as a whole, increases in agricultural production have kept up with increases in population, more or less, over the last two decades. ${ }^{7}$ These increases have not been uniform throughout the world, however, so that in some countries, the food situation may be deteriorating (except as international trade may make up for specific deficits), whereas in other countries, it may be improving. We have seen, however, that the people in the under-

'Id. at ro7.

${ }^{7} \mathrm{O}$. W. Willcox presents evidence that with proper scientific farming, vast increases in food are theoretically possible. Therefore, a greatly inicreased population can be fed, particularly if the people are willing to subsist on a diet of cereals almost exclusively. See Willcox, Footnote to Freedom from Want, 7 Agriculture \& Food Chemistry 813 (1959). 


\section{TABLE VI}

Estimated Population Growth and Increase in Agricultural Production; Selected Countries: Midde i930's-Middle I950's (percentage)

\begin{tabular}{|c|c|c|c|}
\hline \multirow{2}{*}{ Country } & \multicolumn{2}{|c|}{ INOREABE } & \\
\hline & Population $^{2}$ & $\begin{array}{l}\text { Agricultural } \\
\text { Production }\end{array}$ & \\
\hline 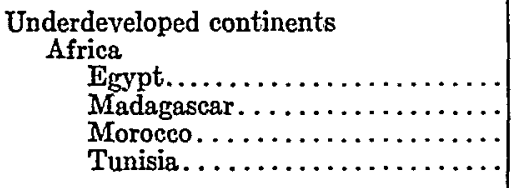 & $\begin{array}{l}47 \\
27 \\
56 \\
44\end{array}$ & $\begin{array}{l}34 \\
30 \\
44 \\
20\end{array}$ & \\
\hline 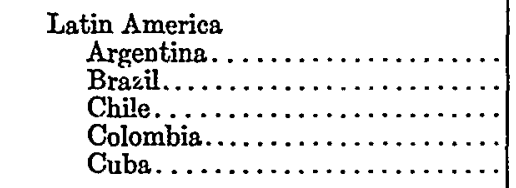 & $\begin{array}{l}47 \\
57 \\
44 \\
54 \\
45\end{array}$ & $\begin{array}{l}21 \\
48 \\
36 \\
84 \\
52\end{array}$ & \\
\hline 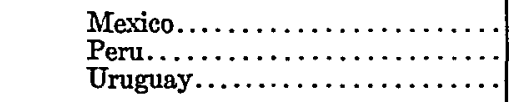 & $\begin{array}{l}64 \\
45 \\
29\end{array}$ & $\begin{array}{r}105 \\
59 \\
38\end{array}$ & \\
\hline 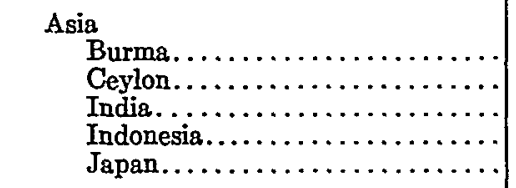 & $\begin{array}{l}28 \\
56 \\
29 \\
25 \\
30\end{array}$ & $\begin{array}{l}16 \\
58 \\
21 \\
19 \\
27\end{array}$ & \\
\hline 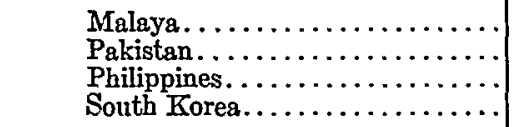 & $\frac{50}{48}$ & $\begin{array}{r}42 \\
13 \\
46 \\
6\end{array}$ & . \\
\hline 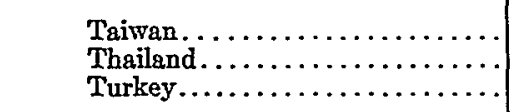 & $\begin{array}{l}69 \\
48 \\
49\end{array}$ & $\begin{array}{l}30 \\
85 \\
70\end{array}$ & $\begin{array}{l}\because \\
\because \\
\because\end{array}$ \\
\hline 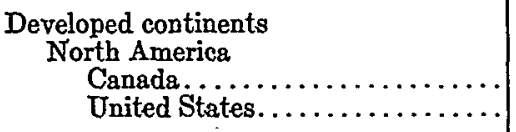 & $\begin{array}{l}41 \\
30\end{array}$ & $\begin{array}{l}65 \\
48\end{array}$ & \\
\hline 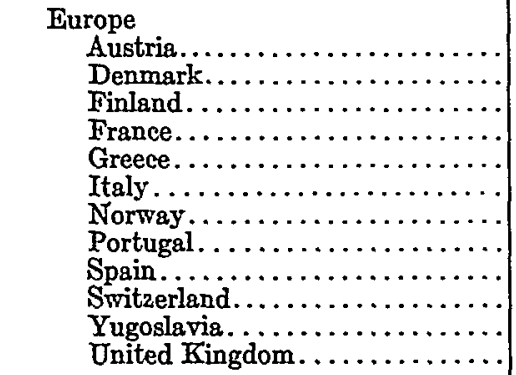 & $\begin{array}{r}3 \\
20 \\
18 \\
5 \\
17 \\
14 \\
19 \\
21 \\
18 \\
20 \\
19 \\
9\end{array}$ & $\begin{array}{r}16 \\
35 \\
37 \\
23 \\
40 \\
37 \\
26 \\
34 \\
1 \\
20 \\
11 \\
59\end{array}$ & \\
\hline
\end{tabular}

Notes: - Percentage change 1935 to 1955

b Percentage change 1934-38 to 1955/56-1956/57.

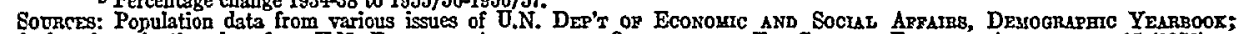

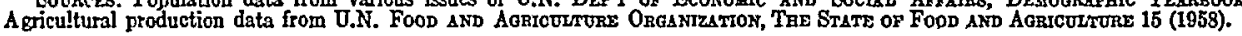


developed areas consume, on a per capita basis, between one-quarter and one-third less food than do the people of the developed areas. Hence, in order to improve the food situation in the underdeveloped areas, production must increase far more rapidly than does population. Ideally, there should be an immediate increase of some twenty-five per cent, with no increase in population.

\section{Education and Literacy}

The majority of the adults in the underdeveloped areas are either completely illiterate or have had very little schooling; furthermore, in too many of these countries, the majority of the children of school age do not attend school-as is shown in table seven. Japan is an exceptional instance; almost all of the adults have had, as a minimum, some six or seven years of schooling, and almost all of the children of school age were attending school in the early 1950's. The population of the developed parts of the world, in contrast with the underdeveloped (excluding Japan), have had significantly more education.

Now, what about long-term trends? We can compare the proportion of children aged seven to fourteen, who were attending school with the proportion of their parent generation, the adults aged thirty-five to forty-four, who reported having had no schooling, as of the early r $95^{\circ}$ 's. If there are any trends toward increased education from one generation to the next, this will be seen by comparing the proportion of children not attending school with the proportion of parents who had no schooling. If the first figure is significantly lower, we can assume that there is a trend toward increased schooling.

Such a comparison suggests that educational progress is being made in a number of countries. In the Philippines, for example, only thirty-five per cent of the children in the early 1950's were not attending school. Of their parents, however, about fifty per cent had no schooling. In Turkey, sixty-five per cent of the children were not attending school, as compared with about eighty-three per cent of their parents who had no schooling. In other countries, on the other hand, there seems to have been but little, if any, progress. Thus, in Guatemala, for example, seventysix per cent of the children were not attending school, and seventy-one per cent of their parents had no schooling.

During the I950's, the numbers of children enrolled in schools have increased significantly in many of the underdeveloped countries, as well as in the United States and other developed areas. It is probable also that there has been an increase in the proportion of the school-age population attending school in a number of countries. Despite such favorable changes, however, two factors are clear: ( $\mathrm{r}$ ) The population of reproductive ages during the I960's and 1970's will be almost entirely illiterate in many countries; and in other countries, it will contain substantial numbers of illiterates (except as adult education may change the situation somewhat). (2) Despite the progress made in many countries in increasing school facilities, large 
proportions of children in the underdeveloped areas are either not attending school or obtaining but a very few years of education. The implications of this for the birth rate and population growth follows.

If the only information available were the observed high correlation among the countries of the world between illiteracy and high fertility, we should not be

TABLE VII

Educational Characteristics of Selected Underdeveloped Areas: Early r950's (PERCENTAGE)

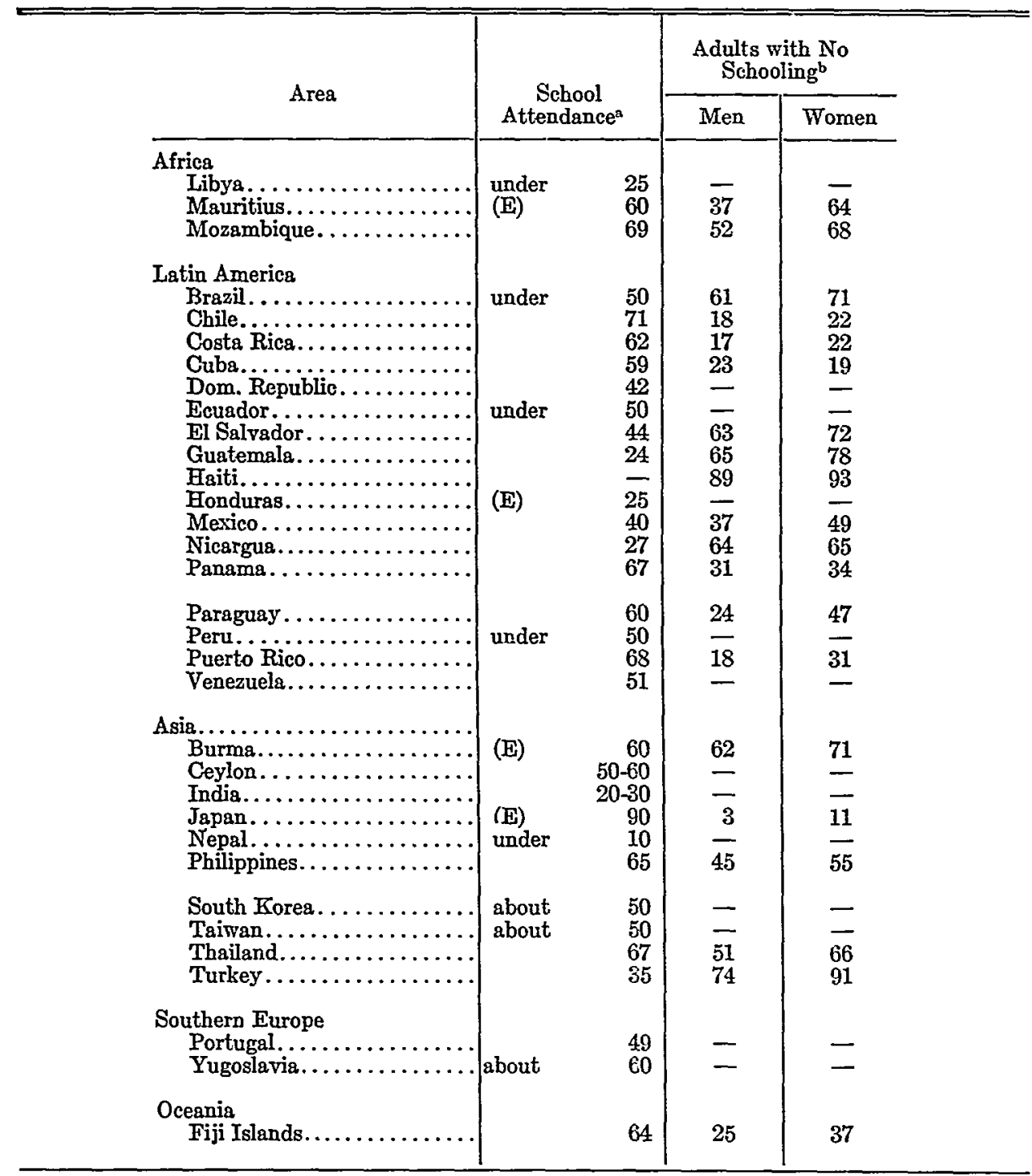

Norzs: a School attendance: percentage of children aged 7 to 14 , attending school; (E) signifies partly estimated.

Thailand aged 10 and no schooling: percentage of adults aged 35 to 44; Japan and Mexico aged 25 and over; Fiji aged 16 and over; Sodnce: U.N. Dep'T of Econourc aND Soctau Afrairs, Devographic Yearboor tables 18, 19 (U.N. Pub. Sales No. 1956. XIII. 5). 
sanguine about the effects of increasing educational levels upon the birth rate. There are, however, many studies for individual countries showing clearly that as the educational level of the population rises, their birth rate decreases. This inverse relationship is not perfect, and there are some exceptions to it.

Furthermore, there is evidence that the most pronounced effects of education occur only when the persons have had several years of schooling. Simply teaching reading and writing is not enough; the children should have gone to school for six to ten years. A study of Puerto Rican women in 1955 showed that those with less than five years of schooling had an average of 4.25 children, those with five to nine years of schooling had 3.58 children, and those with ten years or more of schooling had 2.20 children. A study carried out in Bangalore City, India, showed substantially the same pattern. The average number of children born to women with a high school or college education was substantially less than the average number born to women with lesser education; indeed, educational status below the high school level was unrelated to fertility, women with just a few years of schooling having just as high a fertility rate as illiterate women. ${ }^{8}$

In emphasizing the role of education, we are emphasizing the fact that a high educational level is a necessary, if not sufficient, condition for reducing the birth rate. Peoples living in underdeveloped areas live in cultures in which high fertility is an integral part. In order to reduce fertility, the entire outlook on life, including attitudes towards fertility, must undergo change. Education is a necessary part of such changes; without increased education, economic development alone, as evinced by increases in real product, for example, will not affect the birth rate.

\section{E. Urbanization and Industrial Composition}

The underdeveloped countries, by and large, are much less urbanized than are the developed countries. In the large majority of the underdeveloped countries less than twenty per cent of the population lives in cities containing 100,000 or more persons. On the other hand, in the large majority of the developed countries-i.e., North America, Europe, Oceania, and the Soviet Union-more than twenty per cent of the population lives in such large cities; and in some countries, as the United Kingdom, for example, half or more of the population lives in cities of this size.

The low levels of urbanization in the underdeveloped areas reflect the fact that agriculture is the main industry, the main source of livelihood for the majority of the workers. Comparatively few persons are engaged in manufacturing and other nonagricultural pursuits. This can be seen immediately by noting that Africa, Latin America, and Asia-the underdeveloped continents-contain but one-third the world's total of persons engaged in manufacturing, although they contain some seventy per cent of the world's population.

In terms of the output of goods, as approximately measured by value added by manufacturing, the underdeveloped continents are even further behind the developed

${ }^{8}$ See A. J. Jafpe, People, Jobs and Economic Development 184, 362 (1959). 
areas. Although these underdeveloped areas contain about one-third of the total number of persons engaged in manufacturing, they produce only about twelve per cent of the world's total of manufactured products. These percentages indicate that output per worker in the underdeveloped areas is very low relative to the developed areas. This is borne out by the data showing value added in I948 United States. dollars per person engaged in manufacturing, as follows:

Underdeveloped Areas

Dexeloped Areas

Africa and Middle East...........\$r,800 Northern North America........\$5,900

Latin America............... r,300 Europe ................. 2, roo.

Asia, East \& Southeast.......... 500 Oceania $\ldots \ldots \ldots \ldots \ldots \ldots \ldots .2,800$

Since 1948 , the manufacturing sector has been growing somewhat more rapidly. in the underdeveloped than in the developed areas. It is estimated that in the former areas, the volume of production increased about eight per cent annually from $194^{8}$ to $195^{8}$, and in the developed areas a little over four per cent. We noted previously, however, that population grew faster in the underdeveloped areas-r.9 per cent annually, as compared with 1.2 per cent (in the period I950 to I957). If we allow for differences in the rate of population growth, then the more rapid rate of growth of volume of manufacturing production in the underdeveloped areas-eight per cent annually, as compared with a little over four per cent-is cut somewhat.

F. Participation of the Women in the Working Force

It is difficult to say whether women in underdeveloped areas make a greater or lesser contribution toward the production of goods and services than do women in developed countries. We are certain only of the fact that in underdeveloped areas, as contrasted with developed areas, a larger proportion of the working population is engaged in home industries, including subsistence or semisubsistence agriculture and cottage industries. Hence, the working woman in Africa, Latin America, or Asia: is more likely to be engaged in work at or around her home, whereas the North. American or European woman who works is more likely to leave her home daily while she works at some office or shop totally separated from her home. What does. this aspect of working force behavior have to do with fertility?

It appears that within any one country, the highest birth rate is found among farm women and perhaps other rural women who do not participate in the working: force. Women who carry on economic activities in or around their homes have only slightly lower fertility. These are the women so often found in underdeveloped areas who have very small retail shops in their homes or make cloth or apparel or perhaps some very simply processed food products in or about their homes. Women who leave their homes during the day to work in a modern type of business or industrial establishment, or government office, however, have very much lower fertility. In short, active participation in the modern economic sectors, even within grossly underdeveloped countries, is likely to result in significantly lower fertility. 
Some idea of the possible influence upon fertility when the women work away from home in a modern type of establishment is afforded by the experiences of Puerto Rico and Japan. In Puerto Rico, such women averaged about one-half child less than did women who remained outside of the working force; women who were engaged in home industries had about the same number of children as did women who were not in the working force. In Japan, women engaged in agriculture-one form of home industry-had the highest fertility. Women who were not in the working force or who were engaged in home industries in nonagriculture had slightly lower fertility. The sharpest reduction, amounting to an average decrease of between one-half and one child, occurred among women who left their homes for employment in the modern sectors of the Japanese economy. ${ }^{\circ}$

As far as a nation as a whole is concerned, however, too few women in any of the underdeveloped countries are economically engaged in the modern sectors of the economy to affect the over-all birth rate. Even though half or more of the women may be reported as in the working force, the great majority are engaged in agriculture or other home industries. Thus, for example, in Japan, half of all of the women were reported as in the working force in 1950; only ten per cent of all of the women in the reproductive ages, however, were employed away from home. In Puerto Rico, perhaps fifteen to twenty per cent were employed away from home. For comparative purposes, we may note that in the United States, about one-third of the women in the reproductive ages are so employed.

\section{G. Mortality versus Fertility Rates}

Sometimes it is thought that in underdeveloped areas, people maintain high birth rates because the death rates are so very high; in order to insure having one surviving male heir, it may be necessary to have six or eight births. Hence, so the argument runs, as the death rate decreases and the people see that their children are not dying off at early ages, they will decrease their birth rate.

The available evidence shows that this relationship, if true, holds only with a time lag of at least one generation. Thus, for example-as is shown in table threethe death rate in Latin America, which was between twenty and twenty-five during the I930's, had fallen to about sixteen two decades later, by the middle r950's; the birth rate, however, remained virtually unchanged at forty. Exactly the same relationships seem to hold for other parts of the underdeveloped world, as far as can be determined from the fragmentary data available. Thus, in Egypt, for example, the death rate fell from some thirty-seven in the I930's to perhaps seventeen in the I950's; but the birth rate remained almost unchanged around forty. In Taiwan, too, the death rate during these two decades fell from perhaps twenty to ten, while the birth rate remained over forty.

Id. esp. ch. Io; see also Jaffe \& Azumi, The Birth Rate and Cottage Industries in Underdeveloped Countries (to be published in Econ. Dev. \& Cultural Change). The above pattern was obscrved as controlling for age, marital status, urban-rural residence, and in the case of Puerto Rico, also for education of women. 
We can only conclude that if people have high birth rates in order to compensate for high death rates, then they will reduce their birth rate only after they believe that a permanent drop in the death rate has occurred. This means that at least one generation will elapse between the time that significant decreases in mortality occur and the time that the people have enough confidence to reduce their birth rate. During the course of one generation, however, the population of a country can double, at the prevailing rates of natural increase.

\section{H. Summary}

Some of the most obvious factors that are related to the observed high fertility rates in underdeveloped as compared with developed countries, are: ( $I$ ) the relatively small amounts of inanimate energy consumed for the operation of modern machinery and other power-driven instruments of a technologically-developed society; (2) the attendant low income; (3) the consumption of less, and perhaps lower quality, food; (4) the low educational levels; (5) the relatively small proportions of children of school age who attend school; (6) the lower degree of urbanization; (7) the almost nonexistence of modern manufacturing, with comparatively few exceptions; (8) the very small proportion of women of productive ages who participate in the modern sectors of the economy; and (9) the fact that high mortality rates are associated with high fertility rates.

We have also seen that these factors are gradually changing, and if the trends continue long enough, the underdeveloped countries will resemble the presently developed ones with respect to the above characteristics, and perhaps others-i.e., the transition from underdevelopment to development will have occurred. Within the short run, however-say, the time of one generation from the end of World War II-it does not seem that very much economic growth will have been achieved, or that these factors will have altered sufficiently to diminish the present high rates of population growth. The only immediate effects of the partial development that has occurred in many parts of the world is that the mortality rate has fallen rapidly and the rate of population growth has increased significantly. The socioeconomic matrix, basically, seems largely unchanged as yet in many parts of the world. The present political developments in Africa and other underdeveloped areas, however, may indicate that some far-reaching changes in the socioeconomic matrix may soon begin, if they are not already underway.

It should also be emphasized that to date, and considering the world as a whole, food production has managed to keep up with population growth. There are variations from country to country: in some areas, food production has forged ahead; and in others, population. To the extent that it is possible to distribute food from surplus to deficit areas, we can say that the increasing population has not resulted in a world-wide food deficit. 
What is most important, however, is that little improvement seems to have taken place-again, remembering that there are some exceptions. The people in the underdeveloped areas have too little food (in comparison with the inhabitants of the developed areas) and they are not succeeding in increasing their per capita food supply. The political importance of this fact is immediately obvious. The people in the underdeveloped areas want economic development so that they can improve their lot, including the amount of food available per person. They will not be satisfied with economic advances that simply keep up with population growth. And in order to achieve their goals, they will turn to whatever economic-political system appears to be most promising.

\section{III}

\section{Possible Future Growth}

No one can foretell with exact certainty how many people will be living in the various parts of the world in 1975 or 2000 . All that we can do is to set up a model or series of models and say that if a particular set of socioeconomic trends were to continue, then there would be a specified number of people at some future specified date. This is exactly what United Nations statisticians did. One model that was constructed assumes that fertility rates will change but little from their levels in the I950's; that death rates will decrease; and that, consequently, population will continue to grow rapidly until at least 2000, the terminal year of the estimates. Another model assumes that the various social and economic forces that we have just examined will result in a significant lowering of fertility rates and, consequently, of the rate of population growth.

TABLE VIII

Projected Population of the World by Continents: 1975 AND 2000 (Mrlions) ${ }^{\mathrm{a}}$

\begin{tabular}{|c|c|c|c|c|c|}
\hline \multirow{3}{*}{ REGION } & \multirow{3}{*}{$\begin{array}{c}1957 \\
\text { (estimated) }\end{array}$} & \multicolumn{4}{|c|}{ Projected } \\
\hline & & \multicolumn{2}{|c|}{1975} & \multicolumn{2}{|c|}{2000} \\
\hline & & High & Low & High & Low \\
\hline 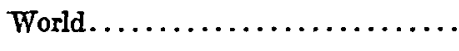 & 2,795 & 3,856 & 3,594 & 6,900 & 4,880 \\
\hline 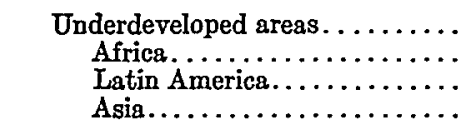 & $\begin{array}{r}1,973 \\
225 \\
192 \\
1,556\end{array}$ & $\begin{array}{r}2,844 \\
331 \\
303 \\
2,210\end{array}$ & $\begin{array}{r}2,617 \\
295 \\
282 \\
2,040\end{array}$ & $\begin{array}{r}5,560 \\
663 \\
651 \\
4,250\end{array}$ & $\begin{array}{r}3,755 \\
420 \\
445 \\
2,800\end{array}$ \\
\hline 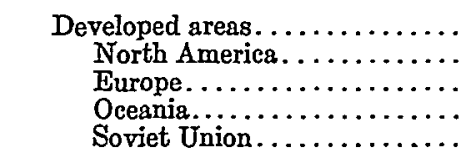 & $\begin{array}{r}822 \\
189 \\
414 \\
15 \\
203\end{array}$ & $\begin{array}{r}1,012 \\
240 \\
476 \\
21 \\
275\end{array}$ & $\begin{array}{r}977 \\
232 \\
458 \\
21 \\
266\end{array}$ & $\begin{array}{r}1,340 \\
326 \\
592 \\
30 \\
395\end{array}$ & $\begin{array}{r}1,125 \\
274 \\
491 \\
27 \\
333\end{array}$ \\
\hline
\end{tabular}

Nors: * Due to rounding, the sums may not necessarily equal the totals shown.

Source: U. N. DeP'T OF EcoNosic and Social Appsins, The Future Growth of Wonld Popdlation (ST/SOA/Eer. A/28) (U.N. Pub. Sales No. 1958. XIII. 2). 
Applying these models-as is shown in table eight-reveals that vast increases in population are possible. The three continents of Africa, Latin America, and Asia, taken together, could increase in population from 2,000,000,000 in 1957 to 2,800,000,000 in 1975 and 5,500,000,000 in 2000 . On the other hand, if they should swiftly urbanize and improve their economies greatly, educate their peoples, and otherwise achieve economic development rapidly, their population could increase from 2,000,000,000 in I957 to only $2,600,000,000$ in 1975 and $3,700,000,000$ in 2000 . In short, it would seem that even under circumstances most favorable toward decreased fertility rates, the number of people in these three continents could almost double within the next forty years.

In the remaining areas of the world-the developed parts-the rate of future population growth is calculated to be much smaller. Population could increase from $800,000,000$ in 1957 to $1,100,000,000$ or $1,300,000,000$ in 2000 . In summary, application of the two models suggests that the most rapid rate of population growth that can be visualized for the developed parts of the world will be significantly lower than the slowest rates of growth that can be anticipated for the underdeveloped parts.

Whether such population increases will eventuate we cannot predict. We can only say that if present socioeconomic trends were to continue, then the above-specified populations would exist. Homo sapiens is notorious, however, for being able to effect his own destiny if he so desires.

\section{IV}

\section{Population Growth and Problems of Capital Investment}

All of the governments and peoples of the world and all of the international agencies are dedicated to the principle of increasing the level of living of everyone in the world, but particularly those in the underdeveloped parts. Occasionally, the peoples of some part of the world help their government understand this ideal by revolting and installing in power a new set of people who promise more vociferously to bring about such economic development. With this goal in mind, we can then ask: How does population growth affect the rate of economic development and improvement in the level of living for the individual and his family?

The most obvious answer, and one that is so simple that it is almost universally ignored, is that any amount of population growth, no matter how little, retards the rate of improvement in the level of living, except under certain conditions to be described later. If an economy is growing but the population remains unchanged in size, then any increase in goods and services, minus that needed for reinvestment purposes, is available for improving the level of living of the people. We must assume, of course, that there is a more or less equitable distribution of the benefits accruing from economic development. If all of the economic gains are taken by a small group of persons for their own personal consumption or are spent on arma- 
ments, then, of course, there will be no improvement in the level of living of the masses.

On the other hand, if there is any amount of population growth, then the increases in goods and services, minus that needed for reinvestment, when divided amongst a larger population, will result in smaller gains per capita in the level of living. With a growing population, however, the problem is even more serious, since a larger proportion of the increased goods and services must be used for further reinvestment purposes rather than being available for personal consumption. In short, a significant portion of the available investment funds-either domestic savings or foreign loans or gifts-must be used to provide the electric power and factories and transportation systems needed to service the increase in population. Additional investment funds, if any are available, can then be used to erect the factories and other enterprises that will result in an improved level of living.

The basic question then becomes: How much investment funds are needed if the economy is to keep up with population growth and also improve the level of living? For this, let us consider the capital-output ratio. The report of the Economic Commission for Asia and the Far East ${ }^{10}$ indicates that three to four units of capital seem to be required in order to increase output by one unit per year. Although there is very much variation from country to country, and from industry to industry, this ratio appears to be useful for a first approximation of the influence of population growth on economic development.

Now let us consider a country that has no population growth, but that is not underpopulated as described below. If such a country can manage to obtain capital investment each year amounting to between three and four per cent of its net national output, then it can raise the per capita income of its population by about one per cent annually. Since underdeveloped countries, by and large, seem able to save something under ten per cent of their national output annually, it would appear that per capita income can be increased about two to three per cent annually on the basis of domestic savings alone, and in the absence of any population growth. If foreign investments can be obtained amounting to another three or four per cent of its net national output, per capita income will increase another one per cent, and so on.

Now what happens if there is population growth of one per cent annually? With a capital-output ratio of three or four, then capital investment amounting to three to four per cent of output must be invested simply to keep up with population growth. During the I950's, the population in the underdeveloped countries was growing at a rate approximating two per cent annually. Six to eight per cent of net national output, then, must be allocated for investment purposes simply to keep up

${ }^{10}$ U.N. Economic and Socias Councie, Economic Commission for Asia and the Far East, Programming Techniques for Economic Development ig-22 (E/CN.I1/L.77) (1960). See also Brand, The World Population Problem, in International Population Conference, 1959 Proceedings 27 et seq. (1960); Paul G. Hoffman, One Hundred Countries and One and a Quarter Birlion People (1960). 
with population growth. Apparently, this is about the ratio of savings that has occurred in underdeveloped countries over long periods of time. If there is to be any increase in per capita income, foreign investments will be needed. Considering the total amount of investment funds that might be available in the developed countries, there does not seem to be enough funds to permit rapid increases in per capita income in all the underdeveloped parts of the world. ${ }^{11}$

Sometimes it is argued that increases in population alone will lead to economic growth, since people are the creators of wealth. To the extent that land and other resources are available that can be exploited by manpower alone and without the use of machinery or inanimate energy, this statement is correct. Under these circumstances, however, the amount of production is only enough for subsistence needs, more or less, and there is no improvement in the level of living for the individual. In order to improve the level of living and produce vastly more goods and services, the output per worker must be increased; this can be done only through the use of modern-or at least semimodern-machinery and techniques, and inanimate energy. These, in turn, require capital investment.

Historically, some underdeveloped countries have developed despite population growth by rigorously limiting domestic consumption and reinvesting as much as possible of the national output. In this way, economic development, but not improvement in the level of living, can be achieved rather rapidly-say, within the space of a generation. This process can lead to political trouble, however, as the masses see economic development, but do not participate in it. Whether there will be political trouble will depend on the political organization of the country. Certainly, in a democracy, in which the people can make their voices heard, it is difficult to prevent the people from participating in any observable economic growth.

There are some underdeveloped countries to which the above description does not apply. These are the ones that are still relatively empty of people and that have considerable natural resources that can be developed only as more people are present, both as workers and consumers. Perhaps parts of Africa, some of the larger islands in the southwest Pacific, and a few other scattered parts of the globe's surface may fall in this category. To the extent that such underpopulated countries do have natural resources, they can import both people and foreign capital.

\section{$\mathrm{V}$}

\section{Population Growth and Employment}

One noticeable feature of underdeveloped countries is that labor is inefficiently utilized under the production systems found there. Much of manufacturing consists of handicraft operations in which hand tools only are used; animals and men rather than machines may be used for transportation; large construction jobs are

${ }^{11}$ Brand, supra note xo. See also ANsLey J. CoAle \& EDGAR M. Hoover, Infunence of Population Growth on Indian Economic Development, in Population Growth and Economic Development in Low-Income Countries pt. 4 (1958). 
often carried on with the use of but very little machinery; trade and the service industries are all highly overstaffed; etc.

When a modern factory or business enterprise is established, labor is used much more efficiently. It has to be so, since modern machinery as well as modern business and managerial practices are introduced. A factory building may be erected mainly by hand labor, but if it is to produce modern goods such as metal products or chemicals or textiles that can compete with similar products manufactured elsewhere, machinery must be utilized. Indeed, many products cannot be made except with modern machinery -as aluminum ingots, for example, or even quick frozen vegetables, or large steel girders. In short, the process of economic development involves the more efficient utilization of labor. In this way, each worker produces more and the level of living can rise.

The result is that very considerable economic growth is possible without the need for any additional manpower. To the extent that the numbers of persons of working-force age increase as a concomitant of population growth, these people will be absorbed into the economy and provided with some type of employment, even if it is only that of an unpaid family worker on a semisubsistence farm. In short, even large-scale economic growth can be accompanied by continuing-and perhaps even increasing-large-scale underemployment. And the faster is the rate of population growth, the faster will be the rate of growth of the population of working force age, and the more difficult it will be to achieve a full employment level.

This process can be illustrated with Puerto Rican experiences. During the years 1940 to 1957, there was considerable migration from Puerto Rico to Mainland United States, as a result of which the island's population grew only about twenty per cent. Gross national product during this decade and a half more than doubled, increasing by 130 per cent. The labor force, however, increased by only about ten per cent. For the decade 1947 to 1957 , for which more information is available, while gross national product increased about two-thirds, there was no change in the numbers of persons employed. There was also very little increase in population during this decade. This large increase in gross national product without any significant increase in the labor force resulted directly from the more efficient utilization of labor in the modern plants and establishments. ${ }^{12}$

Mexico also experienced very rapid economic growth during the decade and a half, I940 to 1955; the volume of production of goods and services more than doubled. The population also increased by fifty per cent, and there seems to have been a piling up of underemployment in various sectors of the economy, especially in agriculture. $^{13}$

Comparison of the two countries provides a glimpse of the role of population growth. In Puerto Rico, with a minimum population growth, annual per capita income, in dollars of a constant purchasing power, almost doubled in about a decade

${ }^{19}$ See A. J. Jaffe, People, Jobs and Economic Developarent ch. 9 (1959).

${ }^{13}$ Id. ch. 13 . 
and a half. In Mexico, during the same period, total economic growth was somewhat greater than in Puerto Rico, but population growth was large, amounting to almost three per cent annually; as a result, per capita income, in pesos of a constant purchasing power, increased only about two-thirds.

How is it that an economy can grow so much, perhaps doubling in a half generation, without requiring additional labor? The answer seems to be as follows:

A modern enterprise can produce very great quantities of additional units or services without employing great numbers of additional workers. When a new establishment does open, some workers are hired. Where are they obtained? Some were employed, some are new entries into the working force. Many, perhaps the majority, however, are persons who simply shifted jobs. Many persons formerly employed in the less productive sectors of the economy, such as semisubsistence agriculture, service industries, trade, and handicrafts, will take advantage of the better-paid job openings created by the new establishment.

Now what happens to these vacated jobs? Very often they can remain unfilled. For example, suppose a son leaves the family farm to take a job in a newly-opened factory; the family members remaining on the farm may be more than sufficient to maintain its output. Or when a self-employed shoeshine boy quits in favor of a factory job, there is no need for a replacement, since the remaining shoeshine boys can shine all the shoes in the community.

Now these persons who have obtained jobs in the modern sector of the economy are earning more than previously and can purchase more. They produce a secondary effect on the volume of goods and services produced by the economy. As long as there are vast pools of underemployed labor, however, the same number of workers can produce increasingly more goods and services. Eventually, they will all become fully employed, at which time, then, further increases in the volume of production will require an increase in the volume of employment.

If there is no increase in the numbers of persons in the working force while this process is going on, eventually everyone will become fully employed. If newcomers are entering the working force as a result of population growth about as rapidly as the underemployed are becoming fully employed, however, there may be no decrease in the size of the ranks of the underemployed.

\section{CONCLUSION}

Population growth in virtually all underdeveloped areas is rapid-some two per cent annually-and promises to become more rapid as death rates are further reduced while birth rates remain at their present high levels. If present rates of population growth should continue, the population of the underdeveloped parts of the world could increase by as much as I75 per cent between 1960 and 2000 , or as little as roo per cent. 
What is so significant about such a rapid demographic growth rate is that it is difficult to force an economy to grow at a rate very much faster than this. Lack of sufficient investment funds, as well as other factors, would seem to make it doubtful that an underdeveloped country can continue to expand its economy at a rate of five to ten per cent annually, decade after decade. American experience over a period of about eight decades-about 1870 to $195^{\circ}-$ provides an average growth rate of about 3.5 per cent annually. If the economies of many of the underdeveloped countries grew at only this rate, they would be doing little more than keeping up with population growth and would be experiencing no increase in per capita income.

Even if a nation's economy grows rapidly-say, seven per cent annually: three per cent for population increase, and four per cent in per capita income-it may require many decades before it becomes semideveloped. Suppose that per capita income was $\$ 100$ in 1960 ; by 1980 , it might be $\$ 200$, and by 2000 , it might reach $\$ 400$; this is exactly one-fifth of American per capita income in 1960. And by 2000, American per capita income should have increased also. Clearly, fertility levels and rates of population growth must be reduced if significant economic progress is to be made rapidly.

There are many factors influencing fertility levels. The growth of the economy is one of these, but it influences fertility only by means of a complex series of interrelationships; economic growth by itself does not automatically lead to an immediate decline in the fertility rate. Another of the elements leading to a lower fertility rate is increased schooling and the provision to everyone of what we should call an elementary school education. As an economy grows rapidly, funds ought to become available for a comprehensive public school system, and the parents should now be able to afford to send their children to school. When the children become the parents of the next generation, they should have a significantly lower fertility rate than their parents had.

The psychological factor of heightened aspirations is another element in the process leading to a reduced fertility rate. Urban life, formal education, modern means of communication, and other factors, all combine with expanding economic opportunities to provide individuals with new aspirations-aspirations that can lead the individual to limit the size of his family. Within this framework of a changing socioeconomic matrix, the provision of adequate contraceptive techniques will make it easier to achieve lower fertility. The provision of birth-control information and materials by itself, however, will contribute little if anything, toward a lower fertility rate, as experience has already demonstrated.

The implications of these remarks, in light of the changes that we observed in part two, above, seem to be that under the best of circumstances, it will still take at least one generation, counting from the end of World War II, before there may be a decided slackening in the rate of population growth and a very significant improvement in the levels of living. In the meantime, the populations of these under- 
developed areas may have doubled, unless war, pestilence, disease, or famine become rampant. Only those few parts of the underdeveloped world that are now grossly underpopulated will benefit significantly from such a doubling of population.

Now, as economic development proceeds, there will be a greatly improved utilization of the workers, and the output per individual will rise very significantly. Furthermore, as the population doubles, more or less, the number of persons of workingforce age will also about double. As a result, it will be extremely difficult to achieve full employment; it is entirely possible that both the numbers of fully employed and of the underemployed will increase. Various measures will have to be taken to spread some of the benefits of the national economic growth to those segments whom the economy cannot employ fully. Clearly, the task of achieving real economic development and substantial increases in the level of living is difficult, but not impossible. 